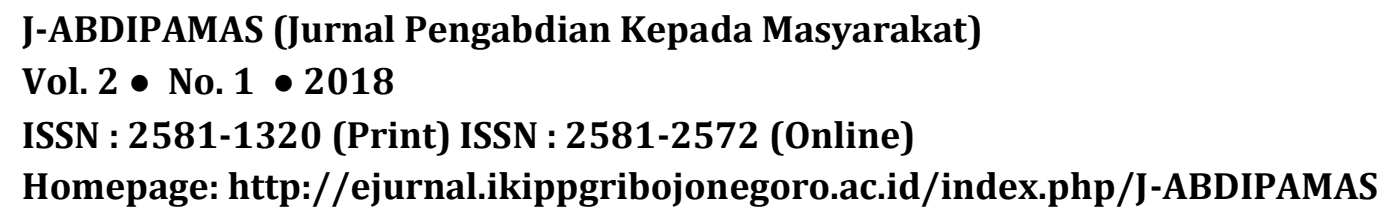

\title{
PELATIHAN METODE PENGEMBANGAN MOTORIK KASAR ANAK USIA DINI PADA GURU PAUD
}

\author{
Romi Cendra ${ }^{1}$, Novri Gazali ${ }^{2}$, Toktong Parulian ${ }^{3}$, Alficandra ${ }^{4}$, Leni Apriani ${ }^{5}$ \\ ${ }^{1}$ Universitas Islam Riau. Email: romicendra@edu.uir.ac.id \\ 2Universitas Islam Riau. Email: novri.gazali@uir.ac.id \\ 3Universitas Islam Riau. Email: toktongparulian@edu.uir.ac.id \\ ${ }^{4}$ Universitas Islam Riau. Email: alficandra@edu.uir.ac.id \\ 5Universitas Islam Riau. Email: leniapriani@edu.uir.ac.id
}

\begin{abstract}
This activity was aimed to educate and train teachers of early childhood education program concerning two key matters for the success of early-age children's gross motor skill development, namely: basic knowledge and skills of early-age children's gross motor skill development methods. This training was provided using direct practice method, a method employed by teachers by practicing in a direct manner in accordance with the materials to be delivered to children. It was expected that through this direct practice activity, children gain experience by directly interacting with objects. This activity was carried out for a period of one day on April 30, 206 from 07.30 to 17.00 outside the effective learning hours. This activity was conducted in Plamboyan, District of Tapung, Regency of Kampar, Province of Riau, with 24 teachers of early childhood education program being participants. From this activity, it was concluded that physical/motoric development is part of basic skill development in kindergarten leading to activities for training children's motoric skills, especially gross motoric skills, including walking, running, leaping, exercising, playing with ball, using tools, dancing, doing rhythmic exercise and combined moves.
\end{abstract}

Keywords: Method Development, Gross Motor Skills

\begin{abstract}
ABSTRAK
Kegiatan ini bertujuan untuk memberikan pembekalan ilmu dan keterampilan kepada para guru pendidikan anak usia dini (PAUD) mengenai dua hal penting untuk sukses dalam mengembangkan kemampuan motorik kasar anak-anak usia dini, yaitu : memberikan pengetahuan dan keterampilan dasar metode pengembangan motorik kasar anak usia dini melalui metode praktik langsung. Metode praktik langsung adalah metode yang dilakukan oleh guru dengan cara melakukan praktek secara langsung sesuai dengan materi yang akan disampaikan kepada anak-anak. Melalui kegiatan praktik langsung diharapkan anak mendapatkan pengalaman melalui interaksi langsung dengan objek.. Program kegiatan dilaksanakan selama satu hari, yaitu pada tanggal 30 April 2016 mulai pukul 07.30 hingga 17.00 di luar jam efektif belajar. Kegiatan ini dilaksanakan di Plamboyan Kecamatan Tapung Kabupaten Kampar Provinsi Riau dengan peserta adalah guru-guru pendidikan anak usia dini (PAUD) yang berjumlah 24 orang. Kesimpulan kegiatan ini yaitu pengembangan fisik/motorik merupakan salah satu bagian pengembangan kemampuan dasar di TK yang mengarah pada kegiatan untuk melatih motorik anak khususnya motorik kasar anak yang terdiri atas gerakangerakan jalan, lari, lompat, senam, keterampilan dengan bola, keterampilan menggunakan peralatan, menari, latihan ritmik dan gerak gabungan.
\end{abstract}

Kata Kunci: Metode Pengembangan, Motorik Kasar 


\section{PENDAHULUAN}

Pada masa kanak-kanak, seluruh komponen perkembangan yang ada pada diri anak akan mengalami perkembangan yang sangat signifikan yang meliputi aspek perkembangan bahasa, fisik motorik, kognitif, sosial emosional dan seni. Seluruh aspek perkembangan tersebut sangatlah penting untuk diberikan rangsangan atau stimulus dari orang tua maupun guru pada saat di sekolah. Salah satu aspek perkembangan yang perlu diberikan stimulus secara proporsional adalah perkembangan fisik motorik. Menurut Suhartini dalam Hakim \& Soekardi (2013:202) perkembangan motorik sangat berkaitan erat dengan kegiatan fisik. Motorik merupakan perkembangan pengendalian gerakan tubuh melalui kegiatan yang terkoordinir antara susunan saraf, otak, dan spinal cord. Perkembangan motorik terbagi menjadi dua yaitu motorik kasar dan motorik halus. Menurut Frankenburg dkk. dalam Ariyana dan Rini (2009:12), motorik kasar adalah aspek yang berhubungan dengan pergerakan dan sikap tubuh. Motorik halus adalah aspek yang berhubungan dengan kemampuan anak untuk mengamati sesuatu, melakukan gerakan yang melibatkan bagian-bagian tubuh tertentu dan dilakukan otot-otot kecil, tetapi memerlukan koordinasi yang cermat.

Dalam pelatihan ini, perkembangan yang diberikan adalah motorik kasar. Kemampuan dan keterampilan motorik kasar perlu mendapatkan perhatian yang seksama, karena pada usia tersebut pertumbuhan dan perkembangan anak perlu menerima berbagai macam rangsangan dari orang tua ataupun guru. Rangsangan ini berguna untuk menunjang perkembangan jasmani dan rohani anak yang artinya juga akan ikut menentukan keberhasilannya dalam mengikuti jenjang pendidikan selanjutnya.

Suyanto (2005:51) berpendapat bahwa perkembangan motorik kasar meliputi perkembangan otot kasar dan halus. Otot kasar atau otot besar ialah otot-otot badan yang tersusun oleh otot lurik. Otot ini berfungsi untuk melakukan gerakan dasar tubuh yang terkoordinasi oleh otak, seperti berjalan, berlari, melompat, menendang, melempar, memukul, mendorong dan menarik. Oleh karena itu gerakan tersebut dikenal dengan gerakan dasar. Pendapat lain dikemukakan oleh Desmita (2007:98) bahwa keterampilan motorik kasar meliputi keterampilan otot-otot besar lengan, kaki, dan batang tubuh seperti berjalan dan melompat. Kemampuan motorik kasar pada anak Taman Kanak-kanak sangat erat kaitannya dengan berbagai aktivitas fisik yang memerlukan energi yang tinggi. Energi tersebut digunakan oleh anak pada masa itu untuk meningkatkan dan melatih keterampilan motorik kasar seperti berlari, melompat, bergantung, melempar bola atau menendangnya. Senada dengan pernyataan tersebut Corbin (Sumantri, 2005:48) menyatakan bahwa perkembangan motorik adalah perubahan kemampuan gerak dari bayi sampai dewasa yang melibatkan berbagai aspek perilaku dan kemampuan gerak. Sehingga aspek perilaku dan perkembangan motorik akan saling berpengaruh.

Pengembangan kemampuan motorik kasar di Taman Kanak-kanak pada dasarnya sangat identik dengan kegiatan pembelajaran melalui bermain, sehingga pemberian rangsangan hendaknya juga dilakukan melalui proses pembelajaran yang di rancang dengan menggunakan permainan agar dapat menciptakan kenyamanan dan kemudahan bagi anak usia dini. Program pengembangan keterampilan motorik kasar pada anak usia dini seringkali terabaikan atau terlupakan oleh orangtua, pembimbing atau bahkan guru. Hal ini lebih dikarenakan anak usia dini belum memahami bahwa pengembangan keterampilan motorik menjadi bagian terpenting dan tak terpisahkan dari kehidupan anak usia dini (Sumantri, 2005:4).

Kegiatan pembelajaran PAUD di Kecamatan Tapung Kabupaten Kampar dilaksanakan selama ini belum terarah pada komponen-komponen kebugaran jasmani yang dapat 
mempengaruhi perkembangan motorik kasar anak. Seperti bermain untuk melatih keseimbangan, koordinasi dan ketepatan anak.

Berdasarkan hasil observasi awal yang telah dilaksanakan, dapat dikatakan bahwa pemberian kegiatan pembelajaran pada kemampuan motorik kasar anak masih belum sesuai dengan apa yang diharapkan, ini disebabkan karena kemampuan guru anak usia dini masih terbatas sehingga mereka tidak memperhatikan bagaimana pola gerak dasar yang benar berjalan, berlari, melompat dan melempar.

Gambaran permasalahan di atas menunjukkan bahwa pembelajaran dalam bidang pengembangan motorik kasar khususnya pada komponen-komponen kebugaran jasmani yaitu berjalan, berlari, melompat dan melempar perlu adanya peningkatan agar anak mampu mengembangkan dan melatih kemampuan dasar yang sudah dimiliki menjadi lebih bermakna dan bermanfaat bagi anak didik. Untuk mengoptimalkan kualitas pembelajaran tersebut perlu dikembangkan media pembelajaran yang dapat menarik minat dan partisipasi anak didik serta dapat membantu anak untuk mengembangkan keterampilan motorik kasar yang sesuai dengan tahapan perkembangannya.

\section{METODE PELAKSANAAN}

Kegiatan ini dilakukan dengan memberikan pembekalan ilmu dan keterampilan kepada para Guru PAUD mengenai dua hal penting untuk sukses dalam mengembangkan kemampuan motorik kasar anak-anak usia dini, yaitu: memberikan pengetahuan dan keterampilan dasar metode pengembangan motorik kasar anak usia dini melalui metode praktik langsung. Metode praktik langsung adalah metode yang dilakukan oleh guru dengan cara melakukan praktek secara langsung sesuai dengan materi yang akan disampaikan kepada anak-anak. Melalui kegiatan praktik langsung diharapkan anak mendapatkan pengalaman melalui interaksi langsung dengan objek. Program kegiatan dilaksanakan selama satu hari, yaitu pada tanggal 30 April 2016 mulai pukul 07.30 hingga 17.00 di luar jam efektif belajar. Kegiatan ini dilaksanakan di Plamboyan Kecamatan Tapung Kabupaten Kampar Provinsi Riau dengan peserta adalah guru-guru PAUD yang berjumlah 24 orang.

Tabel 1. Kegiatan Pelatihan Motorik Kasar Anak

\begin{tabular}{cccc}
\hline No & Waktu & Kegiatan & Pelaksana \\
\hline 1 & $07.30-08.00$ & Verifikasi Peserta Pelatihan & Leni Apriani, M.Pd \\
\hline 2 & $08.00-10.00$ & Pembukaan Oleh Kepala UPTD & H. Aidil, S.H.,M.Si \\
\hline 3 & $10.00-10.30$ & Pemberian Materi 1 & Romi Cendra, M.Pd \\
\hline 4 & $10.30-12.00$ & Pemberian Materi 2 & Novri Gazali, M.Pd \\
\hline 5 & $12.00-13.30$ & Ishoma & - \\
\hline 6 & $13.30-15.30$ & Pemberian Materi 3 & Alficandra, M.Pd \\
\hline 7 & $15.30-16.00$ & Ishoma & - \\
\hline 8 & $16.00-17.00$ & Pemberian Materi 4 (Latihan Praktek) & Toktong Parulian, M.Or \\
\hline
\end{tabular}

Alur pelaksanaan kegiatan dapat dilihat pada tabel 1. Kegiatan dimulai dengan verifikasi peserta pelatihan yaitu Guru PAUD yang berjumlah 24 orang. Setelah itu kegiatan secara resmi dibuka oleh Kepala UPTD Kecamatan Tapung Kabupaten Kampar. 
Selanjutnya memberikan materi tentang motorik kasar melalui media power point. Terakhir, mempraktekkan motorik kasar seperti gerakan-gerakan jalan, lari, lompat, senam, keterampilan dengan bola, keterampilan menggunakan peralatan, menari, latihan ritmik dan gerak gabungan.

\section{HASIL DAN PEMBAHASAN}

Kegiatan pengabdian kepada masyarakat ini berjalan lancar. Pihak UPTD Kecamatan dan guru-guru PAUD se Kecamatan Tapung Kabupaten Kampar memberi sambutan dan kerja sama yang baik. Adapun rangkaian kegiatan pengabdian kepada masyarakat ini sebagai berikut:

\section{a. Pembukaan Oleh Kepala UPTD}

Sasaran kegiatan pengabdian kepada masyarakat ini adalah guru-guru PAUD se Kecamatan Tapung Kabupaten Kampar. Acara dibuka oleh Kepala UPTD Kecamatan Tapung Kabupaten Kampar.

\section{b. Penyampaian Materi Oleh Tim Pengabdian Kepada Masyarakat}

Materi yang disampaikan oleh Tim Pengabdian Kepada Masyarakat berisi tentang keterampilan motorik kasar meliputi keterampilan otot-otot besar lengan, kaki, dan batang tubuh seperti berjalan dan melompat. Pada saat melakukan pelatihan, guru PAUD sangat antusias dalam mengikuti pelatihan dengan banyaknya pertanyaan mengenai motorik kasar anak didiknya, banyak guru PAUD yang selama ini dalam memberikan motorik kasar anak didiknya mereka tidak melihat benar atau salah anak didiknya dalam melakukan motorik kasar sehingga kenyataan di lapangan kecenderungan Guru PAUD yang penting anaknya bergerak, benar atau salah motorik kasarnya seperti melompat (bagaimana posisi tumpuan, ayunan dan mendarat kaki ketika melompat) tidak diperhatikannya.

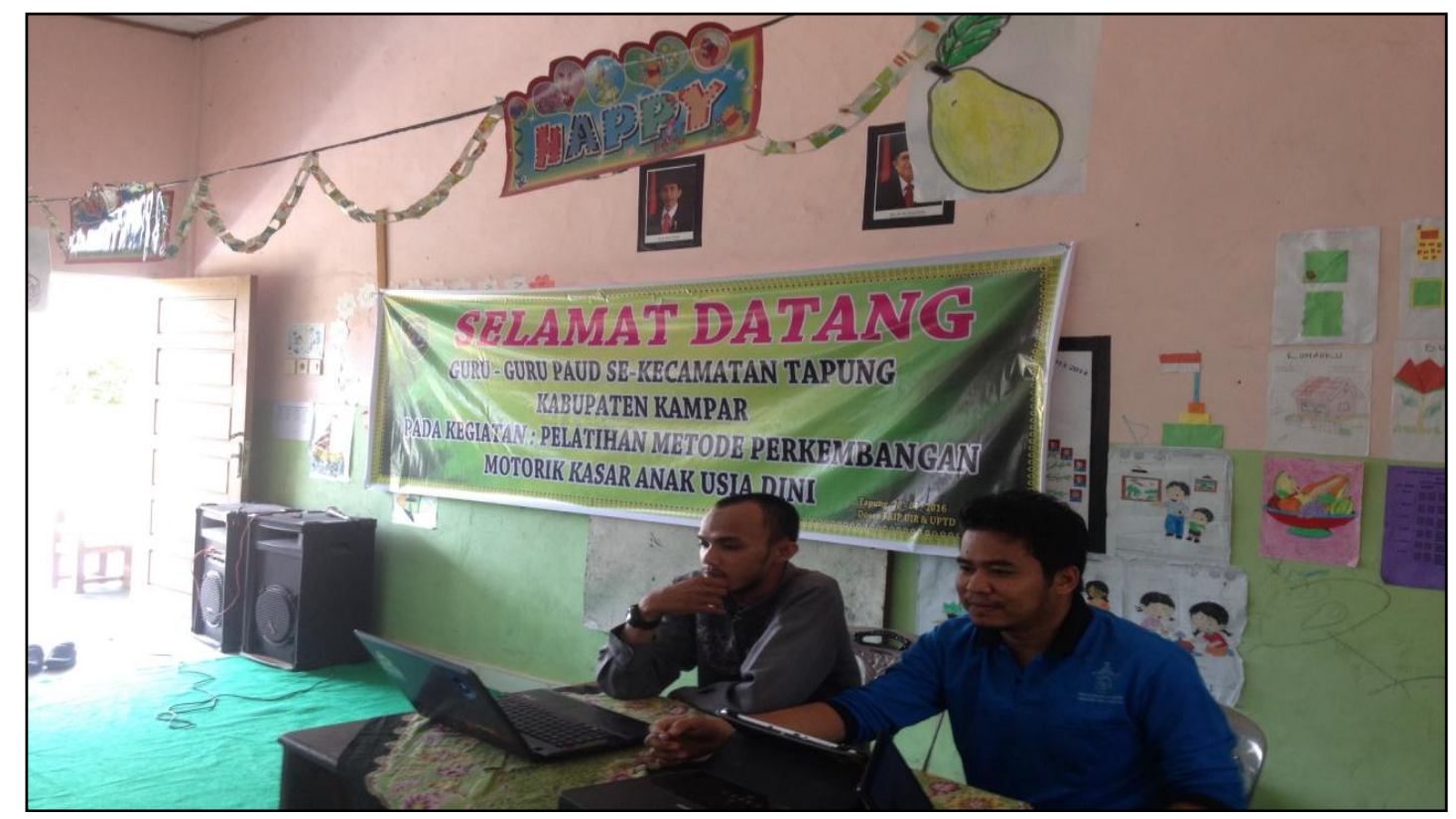

Gambar 1. Tim Pengadian Kepada Masyarakat Memberikan Materi Motorik Kasar 
c. Memberikan Latihan Praktek Oleh Tim Pengabdian Kepada Masyarakat

Latihan praktek yang diberikan oleh Tim Pengabdian Kepada Masyarakat seperti gerakan-gerakan jalan, lari, lompat, senam, keterampilan dengan bola, keterampilan menggunakan peralatan, menari, latihan ritmik dan gerak gabungan.

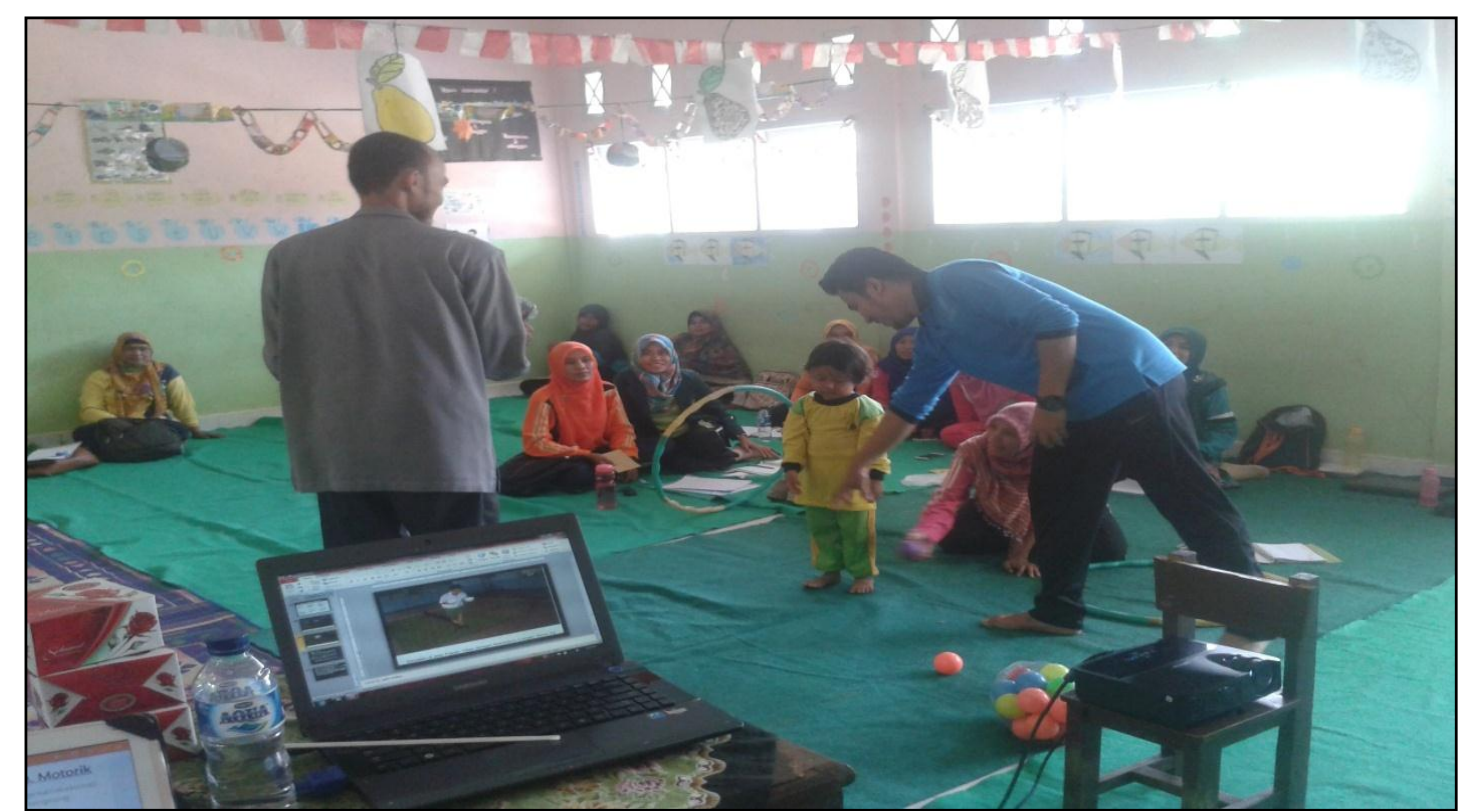

Gambar 2. Tim Pengadian Kepada Masyarakat Mempraktekkan Gerakan Motorik Kasar

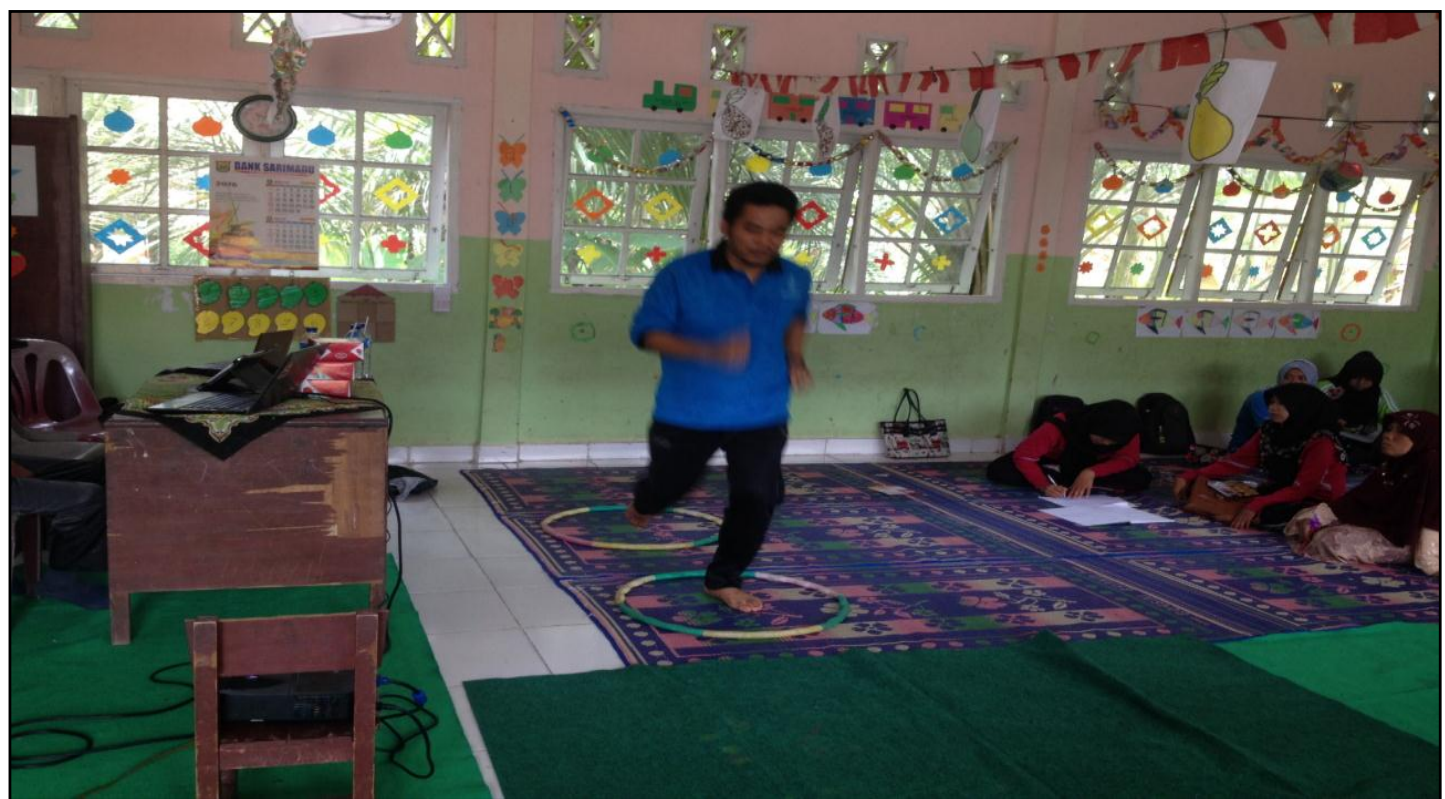

Gambar 3. Tim Pengadian Kepada Masyarakat Mempraktekkan Gerakan Melompat

\section{SIMPULAN}

Pengembangan fisik/motorik merupakan salah satu bagian pengembangan kemampuan dasar di TK yang mengarah pada kegiatan untuk melatih motorik anak khususnya motorik kasar anak yang terdiri atas gerakan-gerakan jalan, lari, lompat, senam, keterampilan dengan bola, keterampilan menggunakan peralatan, menari, latihan ritmik dan gerak gabungan. 
Gerakan-gerakan dasar dilatihkan sedemikian rupa secara bertahap sehingga dikuasai oleh anak didik. Guru harus mencontohkan setiap gerakan dan anak didik diberi kesempatan untuk melakukannya bersama guru sesuai instrument dalam yang telah diberikan. Guru tidak hanya memberikan instruksi dan anak yang melakukan, akan tetapi kegiatan tersebut dilakukan bersamasama. Gerakan juga harus bervariasi sehingga suatu permainan terdiri dari beberapa elemen gerakan dasar.

Agar kegiatan pengembangan fisik/motorik dapat terlaksana dengan baik, maka anak didik dituntut memiliki perhatian dan daya tangkap yang baik pula, seperti kecepatan bereaksi, kesanggupan kerjasama, disiplin, jujur, dan lain-lain, sesuai dengan kemampuan anak didik. Manfaat kegiatan ini bagi guru dan siswa adalah sebagai berikut:

a. Bagi guru

Diharapkan guru PAUD memiliki pengetahuan serta strategi metode pengembangan motorik kasar pada anak usia dini serta mampu menciptakan suasana baru dengan kondisi apapun, dengan memodifikasi bentuk aktivitas yang sudah ada untuk disajikan dengan cara yang lebih menarik dalam proses pembelajaran motorik pada tahap awal. Selain itu, para guru PAUD memberikan keterampilan dasar pengembangan motorik kasar anak-anak usia dini sebagai upaya memberikan kekayaan kemampuan serta keterampilan pada siswanya.

b. Bagi siswa

Agar peserta didik kaya akan keterampilan dan kemampuan motorik terkhusus motorik kasar anak dengan esensi aktivitas yang lebih menarik dan menggembirakan yang dapat mengembangkan tiga aspek penting dalam masa pertumbuhan dan perkembangannya diantaranya kognitif, afektif dan psikomotor. situasi tersebut diharapkan peserta didik akan memiliki pengalaman yang banyak dan beragam.

\section{DAFTAR RUJUKAN}

Ariyana, D \& Rini, N. R. (2009). Hubungan Pengetahuan Ibu Tentang Perkembangan Anak Dengan Perkembangan Motorik Kasar dan Motorik Halus Anak Usia 4-5 Tahun di TK Aisyiyah Bustanul Athfal 7 Semarang. FIKkes Jurnal Keperawatan. Vol. 2, No. 2. Maret. 11-20.

Desmita. (2007). Psikologi Perkembangan. Bandung: PT Remaja Rosdakarya.

Hakim, A.R \& Soekardi, S. (2013). Pengaruh Usia dan Latihan Keseimbangan Terhadap Kemampuan Motorik Kasar Anak Tunagrahita Kelas Bawah Mampu Didik Sekolah Luar Biasa. Journal of Physical Education and Sports. Volume 2, Nomor 1, Juni. 200-204.

Masitoh, dkk. (2005). Pendekatan Belajar Aktif di Taman Kanak- Kanak. Jakarta: Departemen Pendidikan Nasional.

MS. Sumantri. (2005). Model Pengembangan Keterampilan Motorik Anak Usia Dini. Jakarta: Departemen Pendidikan Nasional.

Slamet, S. (2005). Konsep Dasar Pendidikan Anak Usia Dini. Jakarta: Departemen Pendidikan Nasional. 